\title{
Congenital anterolateral bowing of the tibia with ipsilateral polydactyly of the great toe associated with cerebral cyst: a new entity?
}

\author{
Jeroen Breckpot ${ }^{\mathrm{a}}$, Bernard Thienpont ${ }^{\mathrm{a}}$, Christine Vanhole ${ }^{\mathrm{b}}$, Els Van Rossem ${ }^{\mathrm{c}}$, \\ Dominique Van Schoubroeck ${ }^{d}$, Jean-Pierre Fryns ${ }^{a}$, Lieven Lagae ${ }^{c}$, \\ Gunnar Buyse ${ }^{\mathrm{c}}$ and Koen Devriendt ${ }^{\mathrm{a}}$
}

\begin{abstract}
We present two patients with congenital anterolateral bowing of the tibia with polydactyly who had, in addition, cerebral malformations including agenesis of the corpus callosum and a large cerebral cyst. We discuss phenotypic overlap with the acrocallosal syndrome. Clin Dysmorphol 18:195-200 @ 2009 Wolters Kluwer Health | Lippincott Williams \& Wilkins.
\end{abstract}

Clinical Dysmorphology 2009, 18:195-200

\author{
Keywords: acrocallosal, congenital anterolateral bowing of the tibia with \\ polydactyly, minor tibia duplication \\ ${ }^{a}$ Center for Human Genetics, ${ }^{b}$ Neonatology Unit, Departments of ${ }^{\mathrm{c} P e d i a t r i c}$ \\ Neurology and ${ }^{d}$ Obstetrics and Gynaecology, University Hospital Leuven, \\ Leuven, Belgium
}

Correspondence to Dr Koen Devriendt, University Hospital of Leuven Herestraat 49, B-3000 Leuven, Belgium

Tel: +32163459 03; fax: + 3216346051 ;

e-mail: Koen.Devriendt@med.kuleuven.ac.be

Received 5 February 2009 Accepted 16 April 2009

The radiographs of the right leg showed anterolateral bowing in the middle-third of the tibia and a normal fibula. No osseous components were detected in the medial part of the duplicated hallux. Complementary investigations including karyotype, eye examination, and skeletal survey were normal. Computed tomography and MRI of the brain revealed agenesis of the corpus callosum and the presence of a large, interhemispheric cyst, expanding asymmetrically to the left side (Fig. 3).

At the age of 4 months, drainage of the arachnoidal cyst was performed, because of rapidly increasing head circumference $(47.5 \mathrm{~cm}, 2.5 \mathrm{~cm}>97$ th percentile). Pylorotomy was performed at age 6 months. At age 34 months, development, evaluated by means of the Stutsman, revealed a mental age of 32 months, [corresponding to an IQ (intelligence quotient) of 94]. Fine and gross motor development were more delayed. At age 10 years, a full scale Wechsler Intelligence Scale for Childrenrevised edition IQ of 79 was obtained with verbal IQ 78 and performal IQ 80. He followed special schooling for persons with mild learning disabilities. The $6 \mathrm{~cm}$ leg-length discrepancy between both tibias was corrected surgically (Ilizarov) at age 16 years. Currently, at age 19, he has no medical problems. Height is $169.5 \mathrm{~cm}$ (25th percentile), weight $86.2 \mathrm{~kg}$ ( $>97$ th percentile) and head circumference $61.8 \mathrm{~cm}$ ( $>97$ th percentile). Mutation analysis of GLI3 was normal and no chromosomal imbalances were detected by means of a bacterial artificial chromosome/P1-derived artificial chromosome array with $1 \mathrm{Mb}$ resolution performed as described (Menten et al., 2006). 
Fig. 1
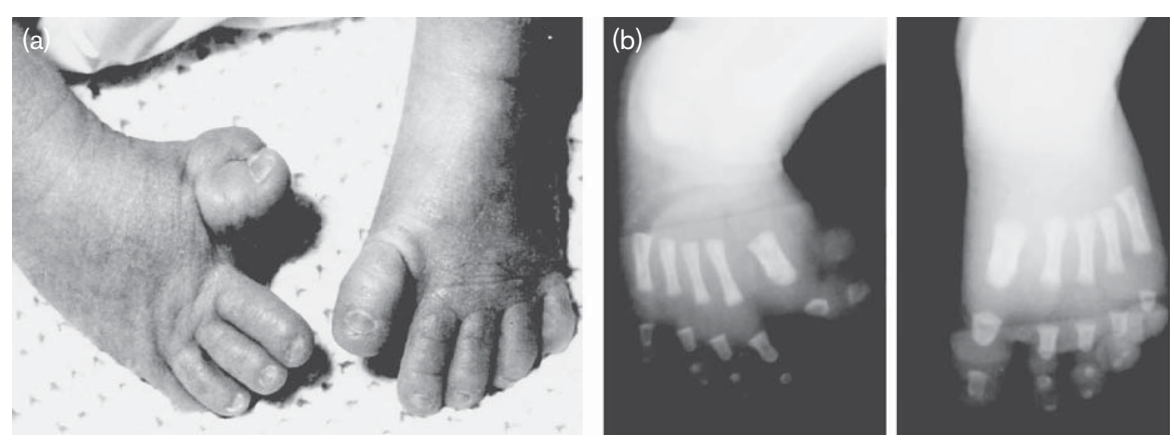

Preaxial polydactyly of the right foot in patient 1 (a). Radiographs show no osseous components in the medial part of the duplicated hallux (b).

Fig. 2
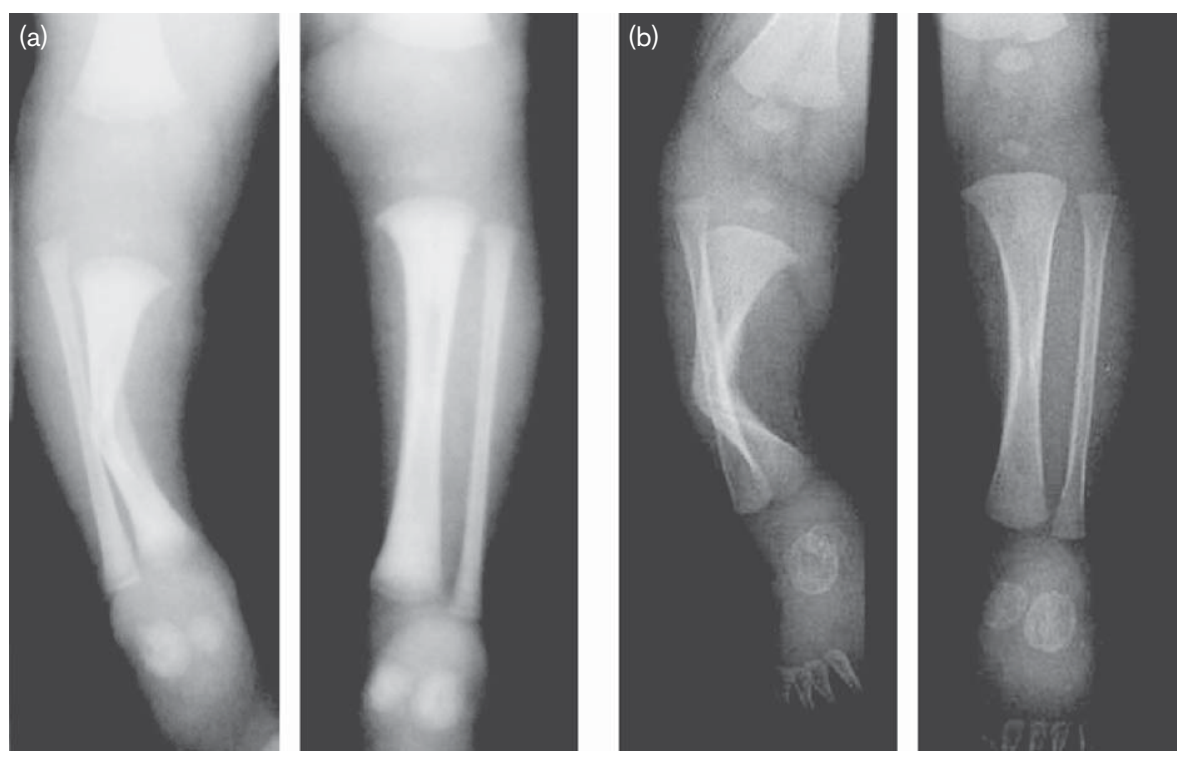

Anterotlateral bowing of the right tibia in patient 1 (a) and patient 2 at age of 6 weeks (b).

Fig. 3
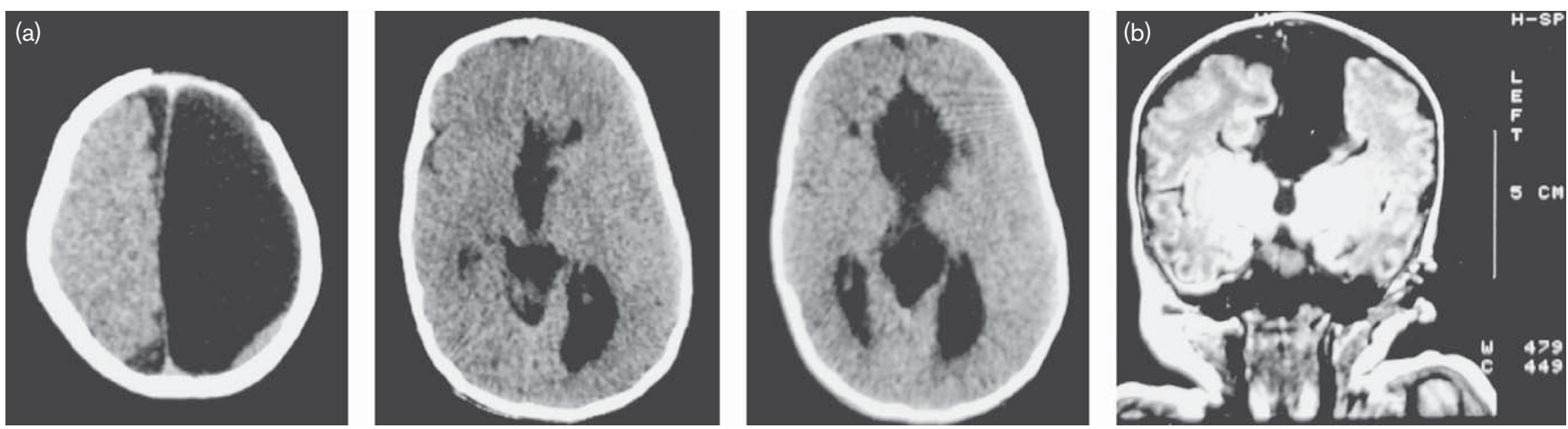

Transverse computed tomography (a) and coronal MRI images (b) of the brain showing a large, interhemispheric cyst, expanding asymmetrically to the left side in patient 1 at the age of 4 months. 


\section{Patient 2}

Patient 2 is the third child of healthy, unrelated parents. Family history is negative with regard to mental handicap or congenital malformations. Bowing of the right lower limb was detected antenatally. During the 34th week of gestation, ultrasound revealed the presence of a large cerebral cyst. He was born at 36 weeks of gestation with weight $2.915 \mathrm{~g}$ (75th percentile), length $47.5 \mathrm{~cm}$ (50th percentile), head circumference $38.3 \mathrm{~cm}$ ( $>97$ th percentile). MRI of the brain showed a large, multicystic mass most likely originating from the third ventricle. There was agenesis of the corpus callosum, aqueduct stenosis, and a hypoplastic right cerebellar hemisphere. Polymicrogyria was noted on the left side, with an aberrant left Rollandic sulcus (Fig. 4).

There were associated limb anomalies. The right tibia was bowed. On radiograph, there was anterolateral bowing at the middle of the tibia, which appeared denser. The fibula was normal (Fig. 2). There was a right preaxial polydactyly with incomplete duplication of the nail of the first ray. Radiographs showed the presence of two phalanges. The second toe was deviated. The left foot appeared normal. The right hand showed clinodactyly of the fifth finger, with an irregular second phalanx. The left hand showed cutaneous webbing between the first and second ray, surgically corrected at the age of 3 months (Fig. 5), and hypoplasia of the distal phalanx of the second finger. Further clinical examination was unremarkable.

At the age of 2.5 months, he presented signs of increased intracranial pressure, with feeding difficulties, and accelerated head growth. Occipitofrontal circumference was $43.3 \mathrm{~cm}$ ( $>97$ th percentile), weight $4.080 \mathrm{~g}$ (25th percentile), and length $53.8 \mathrm{~cm}$ (25th percentile). Computed tomography scan of the brain showed an

Fig. 4
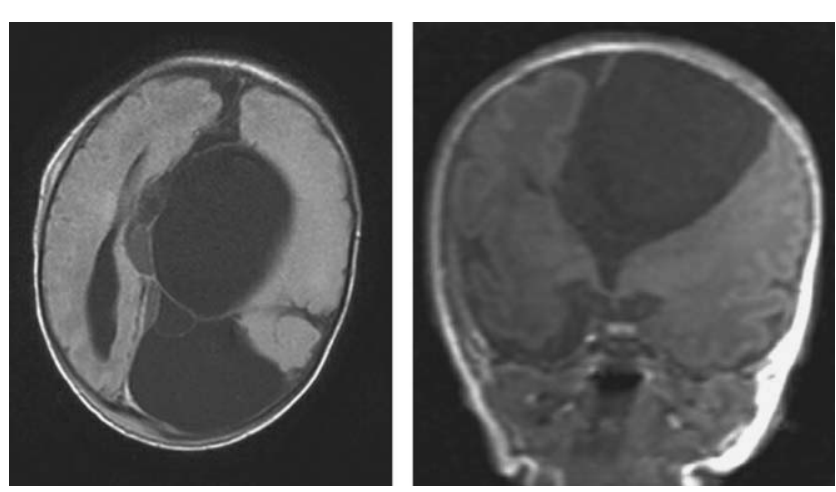

Transverse and coronal MRI images of the brain in patient 2 at birth, showing a large, multicystic mass originating from the third ventricle, and agenesis of the corpus callosum. There is polymicrogyria on the left side, with an aberrant left Rollandic sulcus.
Fig. 5
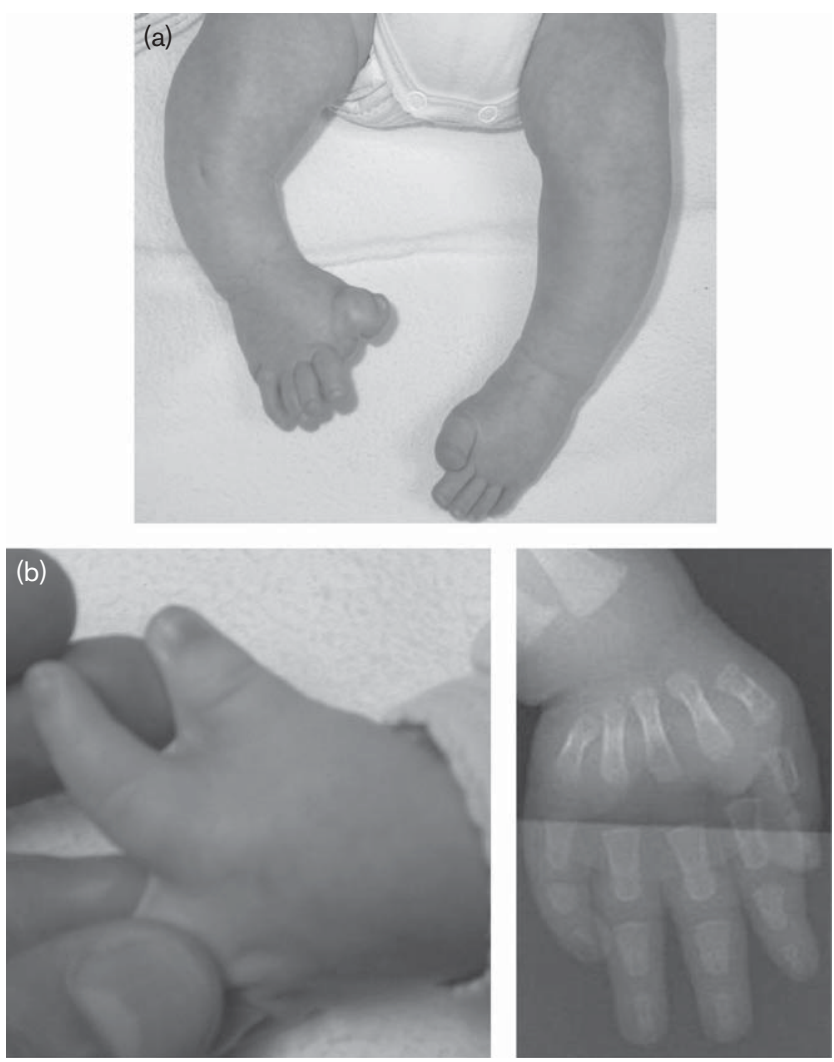

Patient 2. Preaxial polydactyly of the right foot (a) and cutaneous webbing between the first and second ray of the left hand (b).

increased volume of the cerebral cyst, and a cystoperitoneal drainage was performed. After this, he was more alert and feeding difficulties resolved. At age 8 months, he developed absence and myoclonic epilepsy which was multidrug resistant. A nervus vagus stimulator was implanted at the age of 2 years. Bayley Scales of Infant Development-second edition was performed at the age of 11 months. His motor abilities were scored around 6 months, his mental abilities were scored around 7-8 months. At age 1 year, he underwent surgical excision of the supernumerary toe. No causal imbalances were detected by SNP array (Affymetrix 6.0, Santa Clara, California, USA).

\section{Discussion}

The association between unilateral congenital bowing of the tibia and ipsilateral preaxial duplication of the first toe has been reported before in the literature, and is referred to as minor tibia duplication in the London Dysmorphology Database. This is based on the apparent duplication of the tibia on radiographs in the patient reported by Adamsbaum et al. (1991). However, most authors refer to the condition as congenital anterolateral 
bowing of the tibia with ipsilateral polydactyly of the great toe (CABTP). Up to now, and including the present two patients, 21 cases have been described (Newell and Durbin, 1976; Adamsbaum et al., 1991; Watanabe et al., 1992; Weaver et al., 1996; Kitoh et al., 1997; Bressers and Castelein, 2001; Manner et al., 2005; Lemire, 2007; Evans et al., 2008). In none of them, additional major malformations were observed and all reported cases to date have been sporadic (Table 1). In several instances, minor anomalies of the hands were associated, such as cutaneous syndactyly and clinodactyly of fifth fingers. Broad thumbs were also noted. The anomaly of the big toe is strikingly similar in all cases; there is a partial duplication and marked varus position of the first toe. Moreover, the condition is unilateral in all instances. However, unlike these previously reported cases, the present two patients have, in addition, a large intracranial cyst, with associated agenesis of the corpus callosum, and one of them also had cortical malformations (polymicrogyria) and refractory epilepsy.

The association of polydactyly and agenesis of the corpus callosum is described in the acrocallosal syndrome. In this condition, polydactyly is seen both in hands and feet, and can be bilateral. The condition is associated with severe mental retardation. Interestingly, in approximately 25\% (10 of 38) of published cases of acrocallosal syndrome, intracranial cysts were observed, including arachnoid (two), porencephalic (three), interhemispheric (two), supratentorial (one), and Dandy-Walker cysts (two). Of interest, these cases often have a less severe mental handicap (Koenig et al., 2002). There is also a preponderance of males, with an observed sex ratio of males 21/females 13 (Koenig et al., 2002). In the literature, some

Table 1 Reported cases of congential anterolateral bowing of the tibia with polydactyly

\begin{tabular}{|c|c|c|c|c|c|c|c|}
\hline Reference & Case no. & Sex & Age & $\begin{array}{l}\text { Lower limb } \\
\text { involved }\end{array}$ & Hand anomaly & $\begin{array}{l}\text { Other limb } \\
\text { defects }\end{array}$ & CT of bowed tibia \\
\hline \multirow[t]{5}{*}{ Adamsbaum et al. (1991) } & 1 & Female & 17 months & Left & Syndactyly, bifid thumb & & Focal tibial duplication \\
\hline & 2 & Male & 12 years & Right & Bilateral clinodactyly V & & $\begin{array}{l}\text { Small postero-medial } \\
\text { cortical split }\end{array}$ \\
\hline & 3 & Male & 10 years & Left & Unilateral clinodactyly $\mathrm{V}$ & & \\
\hline & 4 & Male & 7 months & Right & $\begin{array}{l}\text { Clinodactyly II and III, } \\
\text { broad first ray (right) }\end{array}$ & $\begin{array}{l}\text { Mild equinovarus } \\
\text { (right) }\end{array}$ & \\
\hline & 5 & Male & 6 years & Right & Normal & & \\
\hline \multirow[t]{3}{*}{ Watanabe et al. (1992) } & 1 & ND & ND & ND & $\begin{array}{l}\text { Bilateral broad thumb, } \\
\text { syndactyly, clinodactyly, } \\
\text { central-ray polydactyly }\end{array}$ & & \\
\hline & 2 & ND & ND & ND & Normal & & \\
\hline & 3 & ND & ND & ND & Normal & & \\
\hline \multirow[t]{2}{*}{ Weaver et al. (1996) } & 1 & Male & 9 months & Left & Bilateral camptodactyly V & $\begin{array}{c}\text { Prominent fibular } \\
\text { head }\end{array}$ & \\
\hline & 2 & Male & 6 years & Left & $\begin{array}{l}\text { Bilateral radial deviation } \\
\text { second ray }\end{array}$ & $\begin{array}{l}\text { Prominent fibular } \\
\text { head }\end{array}$ & \\
\hline \multirow[t]{2}{*}{ Kitoh et al. (1997) } & 1 & Male & 13 years & Right & ND & & Posteromedial cortical cleft \\
\hline & 2 & Male & 18 months & Right & ND & & Partial cleft \\
\hline $\begin{array}{l}\text { Bressers and } \\
\text { Castelein (2001) }\end{array}$ & 1 & Male & 17 months & Left & Normal & & $\begin{array}{l}\text { Bony intrusion of posteromedial } \\
\text { cortex into medullary canal } \\
\text { (MRI) }\end{array}$ \\
\hline $\begin{array}{l}\text { Newell and } \\
\text { Durbin (1976) }\end{array}$ & 3 & Male & 3 years & Left & ND & & \\
\hline \multirow[t]{3}{*}{ Manner et al. (2005) } & 1 & Female & $5-6$ years & ND & ND & Prominent fibula head & Focal tibial duplication (MRI) \\
\hline & 2 & Male & $5-6$ years & ND & ND & Prominent fibula head & Focal tibial duplication (MRI) \\
\hline & 3 & Female & $5-6$ years & Right & ND & $\begin{array}{l}\text { Duplicated navicular, } \\
\text { cuneiform and } \\
\text { metatarsal bones, } \\
\text { prominent fibula head }\end{array}$ & Focal tibial duplication (MRI) \\
\hline Lemire (2007) & 1 & Male & 2.5 years & Right & $\begin{array}{l}\text { Radial deviation of } \\
\text { second ray left }\end{array}$ & & $\begin{array}{l}\text { Tapering and cortical thinning } \\
\text { (MRI) }\end{array}$ \\
\hline Evans et al. (2008) & 1 & Male & ND & Right & ND & & \\
\hline \multirow[t]{2}{*}{ This report } & 1 & Male & 19 years & Right & $\begin{array}{l}\text { Cutaneous syndactyly } \\
\text { III-IV }\end{array}$ & & \\
\hline & 2 & Male & 2 years & Right & $\begin{array}{l}\text { Clinodactyly V (right), } \\
\text { cutaneous webbing I-II } \\
\text { (left), hypoplasia distal } \\
\text { phalanx II (left) }\end{array}$ & & \\
\hline
\end{tabular}


cases that have been described as acrocallosal syndrome resemble the present two cases. For instance, Thyen et al. (1992) reported on a boy with bilateral preaxial polydactyly of the feet, with a right club foot and 'tibial recurvation'. There was preaxial polydactyly of the left hand and clinodactyly (left II and V, right III). Agenesis of the corpus callosum with an interhemispheric cyst was also observed. A similar case with unilateral incurvation of the right leg and ipsilateral preaxial polydactyly of the foot was reported by Fernandez et al. (2008) (case 1). This male fetus presented with corpus callosum agenesis with multiple interhemispheric cysts and agenesis of the posterior cerebellar vermis. Both hands showed cutaneous syndactyly IV-V and camptodactyly. In addition, there was an interfrontal extra bone within the anterior fontanel, a typical feature of the murine Xt GLI3 mutant, a homologous mouse model of Greig encephalopolysyndactyly (Hui and Joyner, 1993). Of interest, Elson et al. (2002) reported a case diagnosed with acrocallosal syndrome who carried a GLI3 mutation, suggesting that some cases of acrocallosal syndrome represent the severe end of the spectrum of GLI3 mutations.

The foot anomalies strikingly resemble those seen in oro-facial-digital syndrome type 1 (OFD1), where typically unilateral partial duplication of the big toe is seen, with varus position. Hallucal anomalies are rarely bilateral (Stapleton et al., 1982). Often, brachydactyly and syndactyly of the other toes is observed. Malformations of the hands include clinodactyly, syndactyly, and brachydactyly. Orstavik et al. (1992) reported a case with unilateral duplication of the big toe associated with ipsilateral bowing of the tibia, thought to represent a pseudarthrosis. Central nervous system malformations are frequent, including agenesis of the corpus callosum, cerebellar anomalies as well as abnormal gyration and arachnoidal cysts (Odent et al., 1998).

However, this condition is X-linked dominant, and thus only seen in girls, whereas the present condition shows a striking preponderance in males (13 boys/three girls). Moreover, facial and oral manifestations are typical of OFD1, and are lacking in the patients reported here.

OFD2, an autosomal recessive condition, is characterized by bilateral preaxial polydactyly of the feet. However, central nervous system malformations are rare. In one case, an arachnoidal cyst with vermis hypoplasia was reported (Reardon et al., 1989), and another case had, what was described as unilateral pseudarthrosis of the tibia, associated with bilateral partial duplication of the halluces (case 5 in Fenton and Watt-Smith, 1985). In OFD type IV, tibial dysplasia is a characteristic feature, but it is unlikely that this is a distinct entity (Toriello et al., 1997). Fontaine et al. (1979) reported on a child which represents features of both conditions: unilateral bowing of the tibia with ipsilateral preaxial polydactyly and varus position of the first toe. There was cutaneous syndactyly of fingers IV-V of the right hand and camptodactyly and clinodactyly of the other fingers. There was a postminimus on the right side. The first toe on the left was broadened. In addition, she presented mild oral manifestations of OFD syndrome, that is, multiple upper and lower intraoral frenulae and irregular alveolar ridges. There was no midline cleft lip.

Of interest is the phenotypic overlap with mesomelic dysplasia type Werner (OMIM 18770), featuring symmetrical tibial aplasia, preaxial polydactyly of hands and feet, and a five-fingered hand with absence of the thumb. However, these limb anomalies are usually bilateral and asymmetric. Moreover, several familial cases have been reported suggesting autosomal dominant inheritance with variable expressivity and incomplete penetrance (Richieri-Costa et al., 1990, Goldenberg et al., 2003).

Proximally placed preaxial polydactyly, particularly when associated with segmentation anomalies of the spine and tibial hemimelia, is suggestive of diabetic embryopathy (Adam et al., 2009). However, maternal diabetes was reported only in one case of CABTP (Bressers and Castelein, 2001).

Recently, mutations in the PITX1 gene were shown to cause asymmetric lower-limb malformations in a family with idiopathic clubfoot segregating as an autosomal dominant condition with incomplete penetrance. The proband presented with bilateral preaxial polydactyly of the feet and right-sided tibial hemimelia (Gurnett et al., 2008). No PITX1 mutations were identified in both of our cases.

In conclusion, there exists phenotypic overlap of CABTP and acrocallosal syndrome as well as with certain cases of OFD1/2. This indicates a related pathogenesis. The sporadic occurrence of CABTP and most cases of acrocallosal syndrome contrasts with the hereditary cause of OFD1/2, indicating etiological heterogeneity. However, given the skewed sex ratio in both acrocallosal and CABTP syndromes and remarkable clinical overlap, it is not excluded that both conditions are the expression of a single disorder with variable expression.

\section{Acknowledgements}

J.B. is funded by a PhD grant obtained from the FWO (Fonds voor Wetenschappelijk Onderzoek) - Flanders. The authors thank the patients for their kind cooperation.

\section{References}

Adam MP, Hudgins L, Carey JC, Hall BD, Coleman K, Gripp KW, et al. (2009). Preaxial hallucal polydactyly as a marker for diabetic embryopathy. Birth Defects Res A Clin Mol Teratol 85:13-19.

Adamsbaum C, Kalifa G, Seringe R, Bonnet JC (1991). Minor tibial duplication: a new cause of congenital bowing of the tibia. Pediatr Radiol 21:185-188. 
Bressers MM, Castelein RM (2001). Anterolateral tibial bowing and duplication of the hallux: a rare but distinct entity with good prognosis. J Pediatr Orthop B 10:153-157.

Elson E, Perveen R, Donnai D, Wall S, Black GC (2002). De novo GLI3 mutation in acrocallosal syndrome: broadening the phenotypic spectrum of GLI3 defects and overlap with murine models. J Med Genet 39:804-806.

Evans JA, Ciano M, Zackai EH (2008). Congenital anterolateral tibial bowing with polydactyly: is this associated hallux varus the clue to pathogenesis? In: David W, editor. Smith workshop on malformations and morphogenesis. Quebec; pp.76.

Fenton OM, Watt-Smith SR (1985). The spectrum of the oro-facial digital syndrome. Br J Plast Surg 38:532-539.

Fernandez C, Soulier M, Coulibaly B, Liprandi A, Benoit B, Giuliano F, et al. (2008). Acrocallosal syndrome in fetus: focus on additional brain abnormalities. Acta Neuropathol 115:151-156.

Fontaine G, Hadrzynski C, Walbaum O, Delattre P (1979). Mohr syndrome and unilateral bowing leg (author's transl). Ann Pediatr (Paris) 26:564-568.

Fryns JP, Spaepen A, Grubben C, van den Berghe H, Casaer P (1991). The variable clinical spectrum and mental prognosis of the acrocallosal syndrome. $J$ Med Genet 28:214-215.

Goldenberg A, Milh M, de Lagausie P, Mesnage R, Benarif F, de Blois MC, et al. (2003). Werner mesomelic dysplasia with Hirschsprung disease. Am J Med Genet A 123A:186-189.

Gurnett CA, Alaee F, Kruse LM, Desruisseau DM, Hecht JT, Wise CA, et al. (2008). Asymmetric lower-limb malformations in individuals with homeobox PITX1 gene mutation. Am J Hum Genet 83:616-622.

Hui CC, Joyner AL (1993). A mouse model of greig cephalopolysyndactyly syndrome: the extra-toesJ mutation contains an intragenic deletion of the Gli3 gene. Nat Genet 3:241-246.

Kitoh H, Nogami H, Hattori T (1997). Congenital anterolateral bowing of the tibia with ipsilateral polydactyly of the great toe. Am J Med Genet 73:404-407.

Koenig R, Bach A, Woelki U, Grzeschik KH, Fuchs S (2002). Spectrum of the acrocallosal syndrome. Am J Med Genet 108:7-11.

Lemire EG (2007). Congenital anterolateral tibial bowing and polydactyly: a case report. J Med Case Rep 1:54.
Manner HM, Radler C, Ganger R, Grossbotzl G, Petje G, Grill F (2005). Pathomorphology and treatment of congenital anterolateral bowing of the tibia associated with duplication of the hallux. $J$ Bone Joint Surg $\mathrm{Br}$ 87:226-230.

Menten B, Maas N, Thienpont B, Buysse K, Vandesompele J, Melotte C, et al. (2006). Emerging patterns of cryptic chromosomal imbalance in patients with idiopathic mental retardation and multiple congenital anomalies: a new series of 140 patients and review of published reports. J Med Genet 43:625-633.

Newell RL, Durbin FC (1976). The aetiology of congenital angulation of tubular bones with constriction of the medullary canal, and its relationship to congenital pseudarthrosis. J Bone Joint Surg Br 58-B:444-447.

Odent S, Le Marec B, Toutain A, David A, Vigneron J, Treguier C, et al. (1998). Central nervous system malformations and early end-stage renal disease in oro-facio-digital syndrome type I: a review. Am J Med Genet 75:389-394.

Orstavik KH, Tangsrud SE, Nordshus T, Finnanger AM, Hellum C, Gjessing E (1992). Orofaciodigital syndrome type I in a girl with unilateral tibial pseudarthrosis. J Med Genet 29:827-830.

Reardon W, Harbord MG, Hall-Craggs MA, Kendall B, Brett EM, Baraitser M (1989). Central nervous system malformations in Mohr's syndrome. J Med Genet 26:659-663.

Richieri-Costa A, de Miranda E, Kamiya TY, Freire-Maia DV (1990). Autosomal dominant tibial hemimelia-polysyndactyly-triphalangeal thumbs syndrome: report of a Brazilian family. Am J Med Genet 36:1-6.

Stapleton FB, Bernstein J, Koh G, Roy S III, Wilroy RS (1982). Cystic kidneys in a patient with oral-facial-digital syndrome type I. Am J Kidney Dis 1:288-293.

Thyen U, Aksu F, Bartsch O, Herb E (1992). Acrocallosal syndrome: association with cystic malformation of the brain and neurodevelopmental aspects. Neuropediatrics 23:292-296.

Toriello HV, Carey JC, Suslak E, Desposito FR, Leonard B, Lipson M, et al. (1997). Six patients with oral-facial-digital syndrome IV: the case for heterogeneity. Am J Med Genet 69:250-260.

Watanabe H, Fujita S, Oka I (1992). Polydactyly of the foot: an analysis of 265 cases and a morphological classification. Plast Reconstr Surg 89:856-877.

Weaver KM, Henry GW, Reinker KA (1996). Unilateral duplication of the great toe with anterolateral tibial bowing. J Pediatr Orthop 16:73-77. 